\title{
A Multi-Ethnic Study to Determine the Prevalence of Bony Exostoses Among Residents in Abuja, North Central Nigeria
}

\author{
Seidu A Bello ${ }^{1,2 *}$, Nathan U Ikimi², Olayinka Falola ${ }^{1}$ and Adeoye John \\ Ademola $^{1}$ \\ ${ }^{1}$ Oral and Maxillofacial Surgery Department, State House Clinic, ASO Rock, Abuja \\ Nigeria, West Africa \\ ${ }^{2}$ Cleft and Facial Deformity Foundation (CFDF), Gwarinpa Abuja, Nigeria, West Africa \\ *Corresponding Author: Seidu A Bello, Oral and Maxillofacial Surgery Department, \\ State House Clinic, ASO Rock and Cleft and Facial Deformity Foundation (CFDF), \\ Gwarinpa Abuja, Nigeria, West Africa.
}

Received: February 04, 2020

Published: February 26, 2020

(C) All rights are reserved by Seidu A Bello., et al.

DOI: $10.31080 /$ ASDS.2020.04.0796

\begin{abstract}
Bony exostoses are non-pathological, asymptomatic bony outgrowths in various parts of the upper and lower jaw within the oral cavity. They are differentiated mainly into two groups: torus mandibularis when found on the mandible and torus palatinus when found on the palate; however significant as they can interfere with the retention of dental prostheses, lead to obstructive sleep apnea, limit tongue movements or be used as a source of autogenous bone graft in Implant Dentistry.

This is a descriptive, cross-sectional epidemiological study carried out among 938 subjects in a multi-ethnic setting, within 12 90 years of age, $37.58 \pm 13.3$ (Mean \pm SD), aimed to determine the prevalence of these bony outgrowth. Ethical clearance was obtained from the medical ethics and research committee of the federal capital territory, data collection tool was a pre-tested self-administered questionnaires and analysis was done with Statistical package for social science (SPSS) version 22. Frequency distribution tables were obtained, and chi-square test and students' t-test were used to compare differences between the various groups present. Statistical significance was set at $\mathrm{p}<0.05$.

A prevalence rate of $15.9 \%$ for torus palatinus and $19.3 \%$ for torus mandibularis was recorded in this study with torus palatinus being more present in females $20.5 \%$ than male $9.6 \%$ and this was statistically significant. Also, of statistically significant was torus palatinus for age-group 20 - 29 years of age and torus mandibularis in equally proportion for age- group 30-39years of age at $22.8 \%$ and 40 - 49years of age at $22.8 \%$. There were no statistically significant relations recorded for torus palatinus or torus mandibularis with the ethnic origin of subjects present in this study.

There are reported studies in Nigeria where statistically significant relationship was established between ethnicity and bony exostosis; however, no such relationship was reported in our multi-ethnic study.
\end{abstract}

Keywords: Torus Palatinus; Torus Mandibularis; North-Central Nigeria

\section{Introduction}

Tori and exostoses can be described as non-pathological, asymptomatic bony outgrowths usually seen in various parts of the upper and lower jaw within the oral cavity. They are also known as oral bony harmatomas, hyperostosis or oral bony outgrowths
(OBOs) [1]. Classification is based on their anatomic location, thus when found in the palate it is known as Torus Palatinus (TP) and when found in the mandible, it is called Torus Mandibularis (TM) [2]. Torus Palatinus are located along the midline of the hard palate and are further divided into flat, spindle and nodular types based 
on their shapes [2] while Torus Mandibularis, are usually located in the lower jaw tending to occur bilaterally in the lingual aspect of the mandible above the mylohyoid line, distal to the second mandibular incisors and mesial to the second premolars [3]. Nevertheless, bony exostoses also appear on the labial and vestibular surfaces of jaws (Maxillary or Mandibular exostoses) or on the palatal surface of the maxilla in the molar region unilaterally or bilaterally (Palatal exostoses) [2].

The exact aetiology of these bony masses is unknown and still remains highly controversial [4], however some previous studies have tried to attribute their presence to genetic factors [4,5], functions [6,7] and associated environmental factors [8,9] with none of these statements accepted largely till date [4-9]. Definitive diagnosing of these bony outgrowths involves a combination of both clinical and radiographic examination [10]. These outgrowths typically do not appear in individuals below ten years of age and are associated with slow growth with the outgrowths developing fully in adulthood [11]. Tori and exostoses appear to have the same histologically appearance with normal compact bone which is composed of slightly spongy structure with marrow spaces [1]. The need to determine the histological appearance is typically to differentiate tori from other significant bony lesions such as Osteomas, chondroma, osteoblastoma or osteosarcoma [12].

These clinically asymptomatic bony outgrowths do not usually require any treatment and their presence may be associated with occasional benefits as they serve as a source of autogeneous bone for bone grafting in Implant Dentistry or Periodontal surgery [13]. Some of the situations which warrant their removal include interference with fitting of dental prostheses, limited tongue movements and obstructive sleep apnea [14-15].

The prevalence of Tori in different ethnic groups ranges from $0-66 \%$ for palatine tori and $0-85.7 \%$ for mandibular tori with individuals of Asian descent having a higher prevalence rate than both Caucasians and Negros [16,17]. Maduakor., et al. in a study conducted in South-Eastern Nigeria, reported an overall prevalence rate of $9.7 \%$ with rates of $8.0 \%$ and $4.2 \%$ for TM and TP respectively [18]. In Southwestern Nigeria, prevalence rates reported by several authors are within the range of 3.7\% - 13.6\% [19-21].

The primary aim of this study is to add more evidence to the literatures on the prevalence rate of these oral bony outgrowths in Sub-Saharan Africa with focus on a multi-ethnic setting in Abuja,
North Central Nigeria especially since previous studies to the best of our knowledge had concentrated more attention on a single ethnic group in South-Western and South-Eastern regions of Nigeria.

\section{Methodology}

This is a descriptive, cross-sectional study involving 938 subjects attending the Dental and Maxillofacial facility of the State House Clinic, Abuja as well as four randomly selected private dental clinics within a 1 year period. Subjects included in this study were 12 years old and above who gave consent themselves as adults and parents granted consent for those below 16years of age. Ethical approval was obtained and convenience, non-probability sampling method was used to select these subjects. Those subjects who did not wish to participate in this study after the purpose was explained to them were excluded and their exclusion had no negative consequence on their treatment in these facilities. Data was collected with the aid of self-administered questionnaires which was divided into two sections:

- Section A: Socio-demographic Information of subjects: Clinician noted the age, sex, ethnic background of patients in a Case file. Then he took accurate history of the time of occurrence of tori and noted if there was any associated pain, bleeding, interference with mastication and if any patient had dentures. Also noted was if there had been any decision to remove tori or any psychological challenges occurring as a result of the presence of tori in the patient.

- Section B: Clinical examination of any bony oral outgrowths: Using a dental mouth mirror, each patient was examined by the clinician who had surgical gloves and face mask. Patient was seated in an upright position on the dental chair under the light of the dental chair; site and number of bony oral outgrowth was noted and recorded on a chart.

Data collected were analyzed using Statistical Package for the Social Sciences version 22 (SPSS Inc, USA). Frequency distribution tables were obtained, and chi-square test, students' t-test and ANOVA test were used to compare differences between the groups present. Statistical significance was set at $\mathrm{p}<0.05$.

\section{Results}

$\beta$ the age-group 30 - 39years of age where highest in this study and the female population in this group were also the highest in the study. This could be as a result of female being more conscious of their dental condition which results to increases in dental attendance to the dental clinics. Please note that the numbers in parenthesis represent the standard deviation as calculated. While the 
total number of subjects was nine hundred and twenty-eight (928),

and South-south Nigeria and finally the third group Northern $\mathrm{Ni}$ this was divided into subjects from Southwest Nigeria, South-east geria.

\begin{tabular}{|l|c|c|c|}
\hline Variable & Male (n=397) & Female (n=541) & Total \\
\hline Age group (Years) & & & \\
$<20$ & $22(5.5)$ & $34(6.3)$ & $56(6.0)$ \\
$20-29$ & $44(11.1)$ & $155(28.7)$ & $199(21.2)$ \\
$30-39^{\beta}$ & $147(37.0)$ & $160(29.6)$ & $307(32.7)$ \\
$40-49$ & $97(24.4)$ & $92(17.0)$ & $189(20.1)$ \\
$50-59$ & $75(18.9)$ & $51(9.4)$ & $126(13.4)$ \\
$60-69$ & $7(1.8)$ & $40(7.4)$ & $47(5.0)$ \\
$\geq 90$ & $5(1.3)$ & $9(1.7)$ & $14(1.5)$ \\
Mean \pm SD & $38.96 \pm 11.8$ & $36.56 \pm 14.2$ & $37.58 \pm 13.3$ \\
\hline Ancestral origin & & $(928)$ & $19.1 \%$ \\
Southwest & & 179 & $44.1 \%$ \\
South east/south & & 414 & $36.8 \%$ \\
North & & 345 & \\
\hline
\end{tabular}

Table 1: Age and gender distribution of subjects with Ancestral origin.

$\beta$ the age-group 30-39years of age where highest in this study and the female population in this group were also the highest in the study. This could be as a result of female being more conscious of their dental condition which results to increases in dental attendance to the dental clinics. Please note that the numbers in parenthesis represent the standard deviation as calculated. While the total number of subjects was nine hundred and twenty-eight (928), this was divided into subjects from Southwest Nigeria, South-east and South-south Nigeria and finally the third group Northern Nigeria.

\begin{tabular}{|l|c|c|c|c|}
\hline \multirow{2}{*}{ Gender } & \multicolumn{2}{|c|}{ Palatal torus } & \multirow{2}{*}{ Total } & \multirow{2}{*}{ p-value } \\
\cline { 2 - 3 } Male & Yes & No & & $<0.001^{*}$ \\
Female & $38(9.6)$ & $359(90.4)$ & $397(100.0)$ & \\
\hline Age group (Years) & $111(20.5)$ & $430(79.5)$ & $541(100.0)$ & \\
$<20$ & $0(0.0)$ & $56(100.0)$ & $56(100.0)$ & \\
$20-29 \pi$ & $61(30.7)$ & $138(69.3)$ & $199(100.0)$ & \\
$30-39$ & $58(18.9)$ & $249(81.1)$ & $37(100.0)$ & \\
$40-49$ & $18(9.5)$ & $171(90.5)$ & $189(100.0)$ & \\
$50-59$ & $6(4.8)$ & $120(95.2)$ & $126(100.0)$ & \\
$60-69$ & $6(12.8)$ & $41(87.2)$ & $47(100.0)$ & \\
$\geq 90$ & $0(0.0)$ & $14(100.0)$ & $14(100.0)$ & \\
\hline Ancestral origin & & & & \multirow{2}{*}{0.492} \\
Southwest & $24(13.4)$ & $155(86.6)$ & $179(100.0)$ & \\
South east/south & $65(15.7)$ & $349(84.3)$ & $414(100.0)$ & \\
North & $60(17.4)$ & $285(82.6)$ & $345(100.0)$ & \\
\hline
\end{tabular}

Table 2: Association between Torus Palatinus and socio-demographic characteristics.

$\S$ The association of Palatal Torus with socio-demographic characteristics was statistically significant with females having more than males.

I Also of statistically significant was the relationship of Palatal torus with the age group 20-29years of age.

There was no notable significance in the relationship of Palatal torus with ancestral origin. 


\begin{tabular}{|l|c|c|c|c|}
\hline \multirow{2}{*}{ Gender } & \multicolumn{2}{|c|}{ Exostosis } & \multirow{2}{*}{ Total } & \multirow{2}{*}{ p-value } \\
\cline { 2 - 3 } Male & Yes & No & & \\
Female & $67(16.9)$ & $330(83.1)$ & $397(100.0)$ & 0.108 \\
\hline Age group (Years) & $114(21.1)$ & $427(78.9)$ & $541(100.0)$ & \\
$<20$ & $0(0.0)$ & $56(100.0)$ & $56(100.0)$ & \\
$20-29$ & $41(20.6)$ & $158(79.4)$ & $199(100.0)$ & \\
$30-39^{\dagger}$ & $7(22.8)$ & $237(77.2)$ & $37(100.0)$ & \multirow{2}{*}{$0.002^{*}$} \\
$40-49$ & $43(22.8)$ & $146(77.2)$ & $189(100.0)$ & \\
$50-59$ & $19(15.1)$ & $107(84.9)$ & $126(100.0)$ & \\
$60-69$ & $5(10.6)$ & $42(89.4)$ & $47(100.0)$ & \\
$\geq 90$ & $3(21.4)$ & $11(78.9)$ & $14(100.0)$ & \\
\hline Ancestral origin & & & & \\
Southwest & $35(19.6)$ & $144(80.4)$ & $179(100.0)$ & \multirow{2}{*}{0.223} \\
South east/south & $89(21.5)$ & $325(78.5)$ & $414(100.0)$ & \\
North & $57(16.5)$ & $288(83.5)$ & $345(100.0)$ & \\
\hline
\end{tabular}

Table 3: Association between Torus Mandibularis and socio-demographic characteristics.

† The association of Mandibular Torus and socio-demographic characteristics had no significance with gender but this was statistically significant with the age group 30-39years of age. There was also no notable significance with ancestral origin.

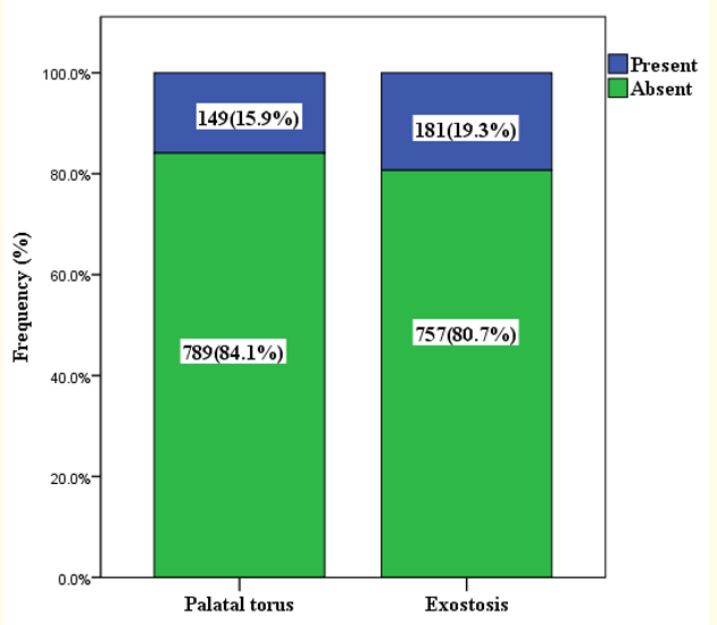

Figure 1: Prevalence of Palatal torus and Mandibular torus (exostosis).

The prevalence of Palatal torus and Madibular torus in our present study were $15.9 \%$ and $19.3 \%$ respectively.

\section{Discussion}

This study was to determine the prevalence of bony exostosis in 928 multi-ethnic subjects residing in Abuja, north central Nigeria. Although, previous studies have suggested tori to have been more commonly seen in the mongoloids than in the Caucasians $[19,22]$ this present study reported a high prevalence of $15.9 \%$ for Torus Palatinus (TP) and 19.3\% for Torus Mandibularis (TM) which is at variance from previous Nigerian study by Adeyemo., et al. [20] who reported a low prevalence of $8.8 \%$ for TM, 7.2\% for TP in the southwestern Nigeria and Agbaje., et al. [21] who also reported a lower prevalence of $1.8 \%$ for TP and $2.5 \%$ for TM in another city in southwestern Nigeria. However, a study conducted in South-eastern Nigeria, reported a prevalence rates of $8.0 \%$ for TM and $4.2 \%$ for TP [18]. A low prevalence of $4.1 \%$ was reported in a different study conducted in Turkey and this study suggested that the diets with the ethnic groups of subjects were possible reasons for low prevalence of tori [17]. On the other hand, high prevalence of $21.0 \%$ was reported for an Israelis population [23], 20.9\% in a United States' population [24] and $32.7 \%$ in a study done in Norway [25], and 
these were attributed to environmental, genetic and other practical factors such as masticatory forces as possible reasons for the high presence of tori.

Furthermore, results from this present study indicated that TP were more common in females $20.5 \%$ than male $9.6 \%$ and this was statistically significant. While the report from the study done in Lagos [20], Nigeria stated that there was no difference of tori in male and female, results from Ibadan [21], south-west Nigeria showed a pattern of higher TM more common in females, though not at significant level. Our result here is consistent with the Turkish study [17] where TP prevalence was statistically significantly higher in females $(5.7 \%)$ than in males $(1.8 \%)$ and these two results are in consonance with other studies [9,17,23,25-27]. While there is no clear reason for the higher TM in females than males, Hamasha., et al. reported that females brush their teeth more than males, smoke less and have a higher dental attendance than male [28], hence their higher population in this study might be a factor.

Also, of statistical significance was that TP was more common in the second decade of life while TM was more common at equal proportion at the third and fourth decades of life. This agrees with the report of Adeyemo., et al. [20], who reported that tori were more at the third and fourth decade of life, although, this is at variance with Agbaje., et al. [21] who reported a peak at the fifth decade of life. Yildiz., et al. [17], gave a closely similar report of the occurrence of tori at peak level at the sixth decade of life.

Ethnicity may have a role to play in the development of tori, this was not clearly established in this study since the dominant ethnic group which is from the north had the largest number of TP at $17.4 \%$ and a combination of south-east/south-south had $21.5 \%$ TM. Also, the study by Adeyemo., et al. [20] and Agbaje., et al. [21] were both conducted in south-western Nigeria and both gave different prevalence that were not closely related. Nevertheless, nutritional factors such as the peculiar diet of an ethnic group $[17,25]$ and genetic factors $[17,23]$ may have a role to play in the formation of tori. It is our opinion that further studies with a larger population could clarify the relationship of tori with ethnicity, diet and hereditary.

\section{Conclusion}

Bony exostosis which is divided into TP and TM has been found to be present in a multi-ethnic population in Abuja, north central Nigeria. The prevalence of tori has been reported to be different among similar ethnic groups living in different geographical areas or different ethnic groups living in the same areas. The inconsistent results of various authors in Nigeria could be due to researching in different geographical locations, using different sample sizes or working with different parameters. Further studies to establish the relationship of sex, diet, genetics and ethnicity to tori is encouraged.

\section{Bibliography}

1. Garcia-Garcia AS., et al. "Current status of the torus palatinus and torus mandibularis". Medicine Oral 15 (2010): 353-360.

2. Chi AC., et al. "Oral and maxillofacial pathology". Elsevier Health Sciences (2008).

3. Leyla BC., et al. "Is There an Association between Torus Mandibularis and Bite Force?" Hacettepe Diphekimliði Fakültesi Dergisi Cilt 29.4 (2005): 15-17.

4. Yoshinaka M., et al. "Prevalence of torus mandibularis among a group of elderly Japanese and its relationship with occlusal force". Gerodontology 31 (2014): 117-122.

5. Johnson CC., et al. "Torus mandibularis: a genetic study". American Journal of Human Genetics 17 (1965): 433-442.

6. Reichart PA., et al. "Prevalence of torus palatinus and torus mandibularis in Germans and Thai". Community Dentistry and Oral Epidemiology 16 (1988): 61-64.

7. Sirirungrojying S and Kerdpon D. "Relationship between oral tori and temporomandibular disorders". International Dental Journal 49 (1999): 101-104.

8. Sasaki H., et al. "Pronounced palatal and mandibular tori observed in a patient with chronic phenytoin therapy: a case report". Journal of Periodontology 70 (1999): 445-448.

9. Al-Bayaty HF., et al. "An epidemiological study of tori among 667 dental outpatients in Trinidad and Tobago, West Indies". International Dental Journal 51 (2001): 300-304.

10. Auskalnis A., et al. "Oral bony outgrowths: Prevalence and genetic factor influence. Study of twins". Medicina 51 (2015): $228-232$.

11. Mirza D., et al. "Frequency of torus palatinus; a study done in a teaching hospital in Karachi". Pakistan Oral and Dental Journal 33.1 (2013): 58-62.

12. Verweij KE., et al. "Multiple lesions in upper jaw". The Netherlands Journal of Medicine 69 (2011): 347-350. 
13. Sonnier KE., et al. "Palatal tubercles, palatal tori, and mandibular tori: prevalence and anatomical features in a US population". Journal of Periodontology 70 (1999): 329-336.

14. Shimahara T., et al. "Mandibular torus with tongue movement disorder: a case report". Bulletin of the Osaka Medical College 53 (2007): 143-146.

15. Saffran AJ and Clark RF. "Torus mandibularis: an unusual cause of obstructive sleep apnea". Journal of Ear Nose and Throat 83 (2004): 324.

16. Pechekina EA and Benfer RA Jr. "The role of occlusal stress and gingival infection in the formation of exostoses on mandible and maxilla from Neolithic China". Homo 53 (2002): 112-130.

17. Yildiz E., et al. "Prevalence of torus palatinus in Turkish school children”. Surgical and Radiologic Anatomy 27 (2005): 368371.

18. Maduakor SN and Nwoga MC. "Prevalence of mandibular and palatine tori among the Ibos in Enugu, South-East Nigeria". $\mathrm{Ni}$ gerian Journal of Clinical Practice 20 (2017): 57-60.

19. Dosumu 00., et al. "The prevalence of palatine and mandibular tori in a Nigerian Population". Odontostomatologie Tropicale 28 (1998): 6-8.

20. Adeyemo WL., et al. "Prevalence and pattern of presentation of mandibular and palatine tori in a Nigerian population". Nigerian Dental Journal 17 (2010): 16-18.

21. Agbaje JO., et al. "Torus palatinus and torus mandibularis in a Nigerian population". African Journal of Oral Health 2 (2005): 30-36.

22. Yaacob H., et al. "The Prevalence of Oral Tori in Malaysians". Journal of Oral Medicine 38 (1983): 40-42.

23. Gorsky M., et al. "Prevalence of torus palatinus in a population of young and adult Israelis". Archives of Oral Biology 41 (1996): 623-625.

24. Kolas S., et al. "The occurrence of torus palatine and torus mandibularis in 2478 dental patients". Oral Surgery, Oral Medicine, Oral Pathology, and Oral Radiology 6 (1953): 1134-1141.

25. Eggen S., et al. "Variation in torus palatinus prevalence in Norway". Scandinavian Journal of Dental Research 102 (1994): 5459.
26. Jainkittivong A., et al. "Prevalence and clinical characteristics of oral tori in 1,520 Chulalongkorn University Dental School patients". Surgical and Radiologic Anatomy 29 (2007): 125131.

27. Tran KT and Shannon M. "Images in clinical medicine. Torus palatinus". The New England Journal of Medicine 356 (2007): 1759.

28. Hamasha AA., et al. "Gender-specific oral health beliefs and behaviors among adult patients attending King Abdulaziz Medical City in Riyadh". The Saudi Dental Journal 30.3 (2018): 226231.

\section{Assets from publication with us}

- Prompt Acknowledgement after receiving the article

- Thorough Double blinded peer review

- Rapid Publication

- Issue of Publication Certificate

- High visibility of your Published work

Website: www.actascientific.com/

Submit Article: www.actascientific.com/submission.php

Email us: editor@actascientific.com

Contact us: +919182824667 